\title{
Mulheres no Tráfico de Pessoas: vítimas e agressoras"
}

\author{
Thaís Dumêt Faria**
}

\begin{abstract}
Resumo
A Criminologia Positivista no Brasil contribuiu para a criação e fortalecimento de estereótipos que influenciam as relações sociais atuais. A Criminologia, enquanto ciência, fortaleceu a idéia do que se chamou "ideal feminino", ou seja, comportamentos padrões que seriam "naturais" e esperados para as mulheres. Um dos temas que mais chamavam a atenção era a sexualidade, o que criou padrões rigídos e preconceitos que perduram até os dias atuais. Esse é um dos motivos que faz com que as mulheres, hoje, vítimas do tráfico para fins de exploração sexual sejam vistas como agressoras e não sejam merecedoras de um tratamento digno e adequado.
\end{abstract}

Palavras-chave: Mulher, Criminologia, Tráfico de Pessoas, Estereótipos.

\footnotetext{
* Recebido para publicação em agosto de 2008, aceito em setembro de 2008. As opiniões expressadas neste artigo são de responsabilidade da autora e não refletem necessariamente as opiniões da Organização Internacional do Trabalho.

*** Advogada, Mestre em Direito pela UnB, Coordenadora do Projeto de Combate ao Tráfico de Pessoas da Organização Internacional do Trabalho. faria@oitbrasil.org.br
}

cadernos pagu (31), julho-dezembro de 2008:151-172. 
Mulheres no Tráfico de Pessoas

Women in the trafficking in persons: victims and offenders

\begin{abstract}
The Positivist Criminology in Brazil, contributed to the creation and strengthening of stereotypes that influence recent social relations. Criminology, as a science, strengthened the idea called "feminine ideal", being, standard behaviors, considered "natural" and expected to women. One of the issues that drew most attention was sexuality, which created rough standards and prejudices that persists until nowadays. This is a reason for the women today, victims of trafficking in persons for sexual exploitation means, to be seen as aggressors and not worthy of a dignified and appropriate treatment.
\end{abstract}

Key Words: Women, Criminology, Trafficking in Persons, Stereotypes. 
Thaís Dumêt Faria

A mulher é apenas um utensílio, e quando seu possuidor é bastante rico para não resentir-se da perda de tal propriedade, ella vale quasi nada, não merece attenção.

Lívio de Castro

Este artigo nasceu de uma situação corriqueira, mas que me fez pensar na mulher em papéis não normalmente vistos $e$ reconhecidos - o de pessoa que comete crimes refutados socialmente. Faço essa ressalva por acreditar que todos nós cometemos crimes, no entanto, alguns deles causam repulsa social, seja pela característica do delito em si, seja por características do, nesse caso, da chamada criminosa. Estava numa reunião discutindo o tema do tráfico de pessoas quando percebi que todas na mesa abordavam as diversas situações mencionando sempre do, ou da, os ou as, no cuidado de enfatizar homens $e$ mulheres. No entanto, sempre que a palavra era agressor, percebi que aparecia no masculino, em todas as situações. Perguntei-me, então, se não haveria mulheres praticando o crime do tráfico de pessoas e percebi que, em grande parte das condenações formais, as mulheres estão envolvidas na rede do tráfico. Ao questionar com uma técnica presente na mesa se não deveríamos falar em agressora, ouvi que normalmente quando a mulher está na posição de agente do tráfico, o está porque existem homens comandando e ela já esteve na situação de vítima. Nesse caso, deveria ser tratada de forma diferenciada por conta da sua suposta vulnerabilidade. Esse tema ficou, então, como algo que precisaria ao menos ser discutido. Algumas perguntas surgiram: será que as mulheres só estão no tráfico porque foram vítimas? Será que sempre existe um homem dando as diretrizes na organização criminosa? As mulheres teriam menos "tendências" criminosas que os homens? As mulheres deveriam ser tratadas de forma diferenciada num processo penal? $\mathrm{O}$ que

${ }^{1}$ Coloco entre aspas por não acreditar em tendência para o crime. 
Mulheres no Tráfico de Pessoas

poderíamos chamar de vulnerabilidade? Todas as mulheres são vulneráveis?

Enfim, dúvidas e questionamentos que, claro, não poderão ser discutidos e muito menos respondidos em um artigo, mas que podem fomentar algumas questões, dentre as quais, como a mulher era vista no chamado mundo do crime. Quais as características que faziam da mulher dotada de periculosidade. Neste artigo, não pretendemos chegar a conclusões sobre a posição da mulher no mundo do crime e, muito menos, como esta deve ou não ser vista e tratada na esfera penal. Pretendemos apenas iniciar uma reflexão de como a mulher foi vista, sobretudo na transição do século XIX para o século XX, e como essa tentativa de classificação da mulher criminosa colaborou para a formação de estereótipos existentes atualmente e que justificam um tratamento diferenciado social ou penal para determinados grupos de mulheres.

Utilizaremos alguns teóricos atuais e dos séculos XIX e XX para dar apoio a algumas reflexões, iniciando pela discussão da Escola Positivista e sua tentativa de classificar os criminosos, passando por alguns estudos específicos sobre a mulher criminosa. Ao final, discutiremos como esses estereótipos influenciam no tratamento da vítima e da autora do crime de tráfico de pessoas. A escolha do crime de tráfico se faz pelo fato desse delito perpassar várias situações preconceituosas onde os estereótipos são, muitas vezes, decisivos para o tratamento e identificação da vítima ou da ré.

\section{Transição das Escolas Penais: \\ o tempo da classificação dos criminosos}

A transição entre a Escola Clássica e a Escola Positivista (século XIX para o século $\mathrm{XX}$ ), que significou a mudança do pensamento abstrato para $\mathrm{o}$ mundo naturalístico e concreto (Pablos de Molina, 1992:103), ocorreu amiúde com estudos simultâneos utilizando metodologias diversas. Enquanto a Escola 
Clássica definia o crime através de uma base legal, com ênfase na liberdade individual, a Escola Positivista rejeitava a definição meramente legal e enfatizava o determinismo ao invés da responsabilidade individual, pregando um tratamento científico para o criminoso com vistas à proteção da sociedade (Alvarez, 2003:45). Segundo Shecaira (2004:76), "a escola clássica enraíza suas idéias exclusivamente na razão iluminista e a escola positivista, na exacerbação da razão confirmada por meio da experimentação".

A "cientifização" da criminologia definiu a transição entre as Escolas Penais, em virtude da necessidade de categorização dos seres humanos, utilizada para justificar os contextos sociais existentes, sobretudo na Europa. Antes do século XIX, havia estudos criminológicos que, no entanto, não foram "elevados" à categoria de ciência, fato que ocorreu com a passagem do método abstrato, dedutivo e formal da Escola Clássica, para o empírico da Escola Positivista. O momento específico do surgimento da criminologia não é algo pacífico, porque os estudos sobre a criminalidade existiam antes do século XIX, no entanto, o mais freqüente é considerar o nascimento da criminologia quando esta passou a ser considerada ciência, fato que ocorreu na transição da Escola Clássica para a Escola Positivista ${ }^{2}$, cujo expoente foi Césare

${ }^{2} \mathrm{Na}$ Escola Positivista havia duas divisões: Nova Escola ou Escola Antropológica e a Escola Crítica ou Eclética. A primeira delas foi a mais influente e com o maior número de estudos. Dessa Escola faziam parte, dentre outros, Lombroso, Ferri, Garofalo, Marro, Sergi, Virgílio, Nina Rodrigues, Viveiros de Castro e Cândido Motta. A Escola Antropológica desenvolveu seus estudos sobre a criminalidade no fim do século XIX, tendo como foco principal os aspectos biológicos que levariam um homem a delinqüir. Consideravam que havia estigmas próprios da criminalidade que seriam fundantes para as ações criminosas. Os fatores sociais, segundo essa Escola, tinham alguma influência nas ações dos criminosos, mas não eram determinantes como os fatores biológicos. Ao tentar explicar o que levava um indivíduo a delinqüir, ancoravam-se na Biologia para desenvolver suas teses. A chamada Escola Crítica ou Eclética, considerava o criminoso produto das condições sociais nas quais estava inserido. As pessoas consideradas "degeneradas" estariam mais susceptíveis às influências do meio. No entanto, a essas pessoas ainda restaria o livre arbítrio de escolher 
Mulheres no Tráfico de Pessoas

Lombroso (1835-1909) com sua obra L'Uomo delinqüente, publicada em 1871.

Os teóricos da Escola Positivista criticavam a criminologia "clássica" pela sua falta de métodos científicos e sobretudo pela ausência de eficácia na contenção da violência crescente, porque, ao estudar o crime como uma "abstração jurídico formal" (Pablos de Molina, 1992:103), desconsiderava o autor e seu contexto social. Dessa forma, faltava-lhes elementos suficientes para a formulação de uma política criminal eficiente. Pablos de Molina (1992:103) afirma que a Escola Clássica:

Foi absolutamente incapaz de oferecer aos poderes públicos as bases e informações necessárias para um programa político criminal de prevenção e luta contra o crime, embora fosse um objetivo de especial importância em um momento de crise econômica e social e de insegurança generalizada

Para que os estudos criminológicos fornecessem elementos à política criminal, era necessário que houvesse um método considerado científico. Foi desenvolvido, então, com maior ênfase ${ }^{3}$, o método empírico indutivo, baseado na observação da pessoa do delinqüente, do seu meio e entorno que pretendia identificar sinais de morfologia simiesca entre os membros dos grupos considerados indesejáveis (Jay Gould, 2003:111). A tese da Escola Lombrosiana era de que existiam espécies humanas com processos de evolução diferentes, de forma que adultos dos

entre cometer ou não um crime. Essa decisão estaria baseada, sobretudo, na responsabilidade moral que todo homem deve possuir. Ou seja, apesar dessa Escola reconhecer que alguns homens estão mais propensos à criminalidade, reconhece neles o livre arbítrio de lutar contra essa "tendência" e não cometer ilícitos. Os partidários dessa Escola, dentre outros, eram: Tarde, Lacassagne, Topinard, Von Liszt, José Hygino e Clóvis Beviláqua.

3 Desde o século XVII, havia outros métodos e áreas do conhecimento interessadas no estudo do crime, como a frenologia (XVIII), a fisionomia (XVI), a psiquiatria (XVIII) e a antropologia (XIX). 
grupos inferiores comparavam-se às crianças dos grupos superiores. As chamadas "espécies inferiores" possuíam características do "homem selvagem" e essa herança levava-os às condutas criminosas.

Lombroso e seus discípulos buscavam identificar essas características, chamadas de estigmas atávicos, para, assim, conseguirem avaliar a periculosidade de cada indivíduo ou de determinados grupos. No entanto, os métodos lombrosianos careciam de metodologia científica e logo começaram a ser criticados. Nem na sua própria amostra de dados, Lombroso conseguiu informações mais concretas. Por essa razão, ele sempre admitiu a possibilidade real de exceções aos resultados do seu método. $\mathrm{O}$ médico, fundador da antropologia criminal, não conseguiu provar a relação desses estigmas com as condutas penalmente puníveis, mesmo tendo feito mais de 400 autópsias e 6000 análises de pessoas consideradas criminosas. Com o passar do tempo, ele fez profundas mudanças nas suas teses, incluindo outras causas para o crime, como o clima, as influências da cidade, as condições sociais, chegando a aproximar-se de antigos opositores. Essas alterações não tiraram, no entanto, a importância de sua tese sobre o criminoso nato. Segundo Darmon (1991:65):

Lombroso parece ter-se tornado um verdadeiro sociólogo. De resto, se em 1876 ele estimava em $95 \%$ a proporção de criminosos portadores do tipo criminalóide, essa proporção cai para $35 \%$ vinte anos depois, em A mulher criminosa. Sem negar os princípios de sua doutrina, o mestre de Turim introduziu nela múltiplas nuanças. Essa reviravolta disfarçada não impediu que o criminoso nato ganhasse fama $e$ se tornasse, no espaço de dois ou três decênios, um dos grandes personagens da arena médica.

Lombroso não conseguiu provar que os sinais atávicos eram definidores da criminalidade, posto que não encontrou uma uniformidade de sinais entre os criminosos que pudessem, 
Mulheres no Tráfico de Pessoas

estatisticamente, comprovar sua tese. Partiu, então, para a identificação de sinais de epilepsia e o que chamava de loucura moral. Uma questão importante é que ele dedicou-se a estudar, com mais profundidade, os homens e mulheres que já estavam segregados socialmente, inclusive através do sistema penal, não levando em consideração o fato de que os grupos estudados eram vítimas do preconceito e da estigmatização social. Nessas pesquisas, ele formulou a tese da hereditariedade criminal, porque percebeu que a maior parte dos presos eram descendentes de pessoas que tinham traços de atavismo e eram criminosos, prostitutas ou parte de outros grupos "indesejáveis". Principalmente no período inicial do seu trabalho, Lombroso desconsiderava a questão social, portanto, não havia uma visão crítica em relação aos grupos excluídos da sociedade e como a miséria e preconceito estigmatizavam algumas pessoas como criminosas. Suas teses vieram a corroborar uma série de preconceitos, sendo a questão racial a que mais sofreu com essa "ciência" da identificação de categorias de seres humanos. Os negros eram sempre considerados menos evoluídos e mais perigosos socialmente.

Não só a população negra sofreu com a definição dos estigmas atávicos, segundo Jay Gould (2003:134),

é impossível calcular a carga adicional que a teoria de Lombroso impôs a milhares de epilépticos: estes se converteram num dos principais alvos dos programas eugênicos, em parte porque Lombroso havia interpretado sua enfermidade como um sinal de degeneração moral.

A Escola Positivista elaborava maneiras de identificar $e$ tratar o criminoso, que não era mais um homem dotado de livre arbítrio e vontade consciente. Dessa forma, instaurou-se a noção de normalidade, quando se afirmou que todo ato criminoso é fruto de um distúrbio individual. Ou seja, quem comete crime é um anormal e necessita de tratamento, sendo normal aquele não 
desviante da norma penal. Outra crítica importante, dos adeptos da Nova Escola, foi no sentido de que a Escola Clássica teve uma atenção especial voltada para a defesa dos direitos individuais, para a normatização da lei penal, visando a diminuição do arbítrio do juiz e a proporcionalidade entre o crime e a pena, abolindo as punições cruéis. Nesse sentido, a defesa da sociedade não era vista como prioridade pela Escola Clássica. Num momento social de aumento da violência, fruto das diferenças sociais cada vez mais latentes na Europa do século XIX, a defesa da sociedade aparecia como providência principal. Essa busca pelos interesses individuais representava um individualismo exarcebado e deixava de lado a proteção social, segundo a Escola Positivista, que priorizou o resgate do "social" e dos direitos da sociedade (Andrade, 2003a:61).

Os métodos precisavam ser desenvolvidos e o que se tornou mais evidente em fins do século XIX, já sob a égide da Escola Positivista, foi o da categorização dos criminosos, tornado público por Lombroso. Surgia uma forma científica de estigmatizar os seres humanos. A criminologia representou o fortalecimento de um discurso que legitimava a desigualdade no campo da lei, ao normatizar o tratamento jurídico-penal diferenciado para setores da população (Alvarez, 2003:33).

A noção de livre arbítrio foi enfraquecida e a tendência era considerar anormais os que cometiam crimes e, portanto, não poderiam ser responsabilizados pelos seus atos, mas sim tratados e privados de sua liberdade para a proteção social. Não havia sentido a punição para um ser humano que não tinha capacidade de controlar seus instintos criminosos. Dessa forma, a pena deixaria de ter um caráter de retribuição do mal para configurar-se numa proposta de tratamento e, nos casos possíveis, de cura.

$\mathrm{Na}$ sua classificação dos criminosos, Lombroso fez uma grande aproximação do direito com a medicina, ao definir algumas pessoas como criminosos natos ou loucos morais. Para estes, o tratamento deveria caber aos médicos e não aos juristas, posto que se tratavam de pessoas doentes. A cura, em muitos 
Mulheres no Tráfico de Pessoas

casos, era considerada impossível, por este motivo, a segregação da sociedade deveria ser perpétua.

"Quanto aos criminosos natos e loucos morais, as mudanças propostas por mim não fariam senão aumentar a segurança social, pois reclamo, para eles, uma detenção perpétua" (Lombroso, 2001:28). Aí reside uma das maiores diferenças entre as Escolas Penais - a Clássica buscava uma normatização total das penas e a Positivista admitia a pena indeterminada. As características definidas por esse "método científico" identificavam como criminosos natos e loucos morais, sobretudo os negros, mestiços e índios. Para eles, o que se buscava era a segregação total e perpétua da sociedade.

Os estudos da criminologia, no momento em que a Europa sofria com a crise social em virtude do fortalecimento do Capitalismo, foram fundamentais para justificar, de forma "científica", as diferenças sociais radicais existentes. "Necessitavase racionalizar as desigualdades e reformular o conceito de liberdade" (Del Olmo, 2004:44). A normatização da sociedade era urgente e a criminologia, considerada como ciência, contribuiu para o controle da população insurgente ao sistema. Batista (2004a:31) afirma que:

Tal criminologia necessariamente tende a tratar o episódio criminal como episódio individual e a respaldar a ordem legal como ordem natural: não por acaso, seus precursores procuraram tematizar um "homem delinqüente", que, ao lado dos "loucos morais" viola a ordem legal, ou um "delito natural", que atinge "sentimentos" encontráveis nas "raças superiores", indispensáveis para a "adaptação do indivíduo à sociedade", isto é, para a manutenção da ordem legal (grifo nosso).

No século XIX, o Estado necessitava das contribuições da ciência para justificar seus atos de controle $e$ as situações de contrastes sociais. Os "revolucionários", criminosos, "anarquistas", enfim aqueles que se insurgiam contra a ordem, eram 
considerados vítimas de uma patologia ou da inferioridade racial. A criminologia, reconhecida como "ciência", teve, como uma das suas funções, legitimar o controle do Estado sobre os insurgentes ao sistema. A função da criminologia não era limitada ao estudo $e$ tratamento dos criminosos, mas à análise das diferenças sociais. Os pobres eram pobres porque inferiores e não em virtude de fatos históricos e sociais. O controle exercido por essa nova ciência não se limitava ao controle de criminosos, mas das categorias consideradas "indesejáveis" para o progresso de uma nação. Para as mulheres, essa nova "ciência" teve o papel de comprovar a suposta inferioridade feminina, além de delimitar os comportamentos aceitos dentro da chamada "normalidade", ou seja, comportamentos que não fossem contrários às normas sociais e aos papéis esperados para as mulheres.

Dessa forma, evitavam-se discussões sobre as medidas sociais ou fatos históricos que poderiam ser responsáveis pelas alarmantes diferenças de classe e violência que a Europa passou a enfrentar na época. No século XIX, a ciência era uma importante aliada para dar credibilidade a uma teoria que ganhava destaque no cenário político da época. Eugenistas ${ }^{4}$ e criminólogos utilizaram o "argumento" científico para legitimar seus estudos e a classe dominante precisava de um respaldo para justificar seus atos. Como aponta Stepan (2005:75), "nem as teorias da ciência, nem as conclusões sociais a elas associadas são simples resultados de investigações neutras".

\footnotetext{
${ }^{4}$ Eugenia vem do grego eugen-s, bem-nascido, e representa as possíveis aplicações sociais do conhecimento da hereditariedade para obter-se uma desejada "melhor reprodução". "Como ciência, a eugenia se baseou nos entendimentos supostamente novos das leis da hereditariedade humana. Como movimento social, envolveu propostas que permitiram à sociedade assegurar a constante melhoria de sua composição hereditária encorajando indivíduos e grupos "adequados" a se reproduzirem e, talvez mais importante, desencorajando ou evitando que os "inadequados" transmitissem suas inadequações às gerações futuras" (Stepan, 2005:09).
} 
Mulheres no Tráfico de Pessoas

A criminologia empreendeu uma crítica aos fundamentos do direito penal liberal, determinando todo o passado do direito penal como um conjunto de erros (Rauter, 2003:25). A Escola Positivista foi a responsável pela "cientifização" do tratamento do criminoso e esse processo ocorreu através do método, fortemente baseado na biologia e na psiquiatria, desenvolvido por Lombroso e seus discípulos.

$\mathrm{Na}$ gama de justificativas para classificar os seres humanos, as mulheres faziam parte do grupo "cientificamente" inferior. Muitos estudos foram feitos para comprovar as diferenças evolutivas entre homens e mulheres. Chamo a atenção para a obra de Livio de Castro - A Mulher e a Sociogenia -, publicada em 1887 no Brasil, que, através de estudos muito similares aos da Escola Positivista, atesta a inferioridade da mulher. Castro defendeu, inclusive, que as mulheres não poderiam ser professoras, pois tinham o mesmo desenvolvimento cerebral de uma criança. Nos seus estudos sobre os crânios $e$ o funcionamento do organismo de homens e mulheres concluiu que:

Historica ou prehistoricamente, nos ultimos tempos da vida intra-ulterina, dos primeiros aos ultimos tempos da vida extra-ulterina, a mulher é menos cerebro do que o homem, ha no homem mais mentalidade do que na mulher. Mas, ao lado dessa affirmação scientifica ha uma affirmação popular que, por se prestar a equivocos, merece um exame. Segundo a crença geral a mulher é mais coração...A mulher não tem o coração mais terno, não é mais sensivel. A mulher tem menos desenvolvido o poder de dominar-se, mas não tem mais desenvolvido o poder de sentir (Castro, 1887:15,21).

O autor discutiu, também, o papel de objeto que a mulher teria perante o homem: "A mulher é apenas um utensílio, e quando seu possuidor é bastante rico para não resentir-se da 
Thaís Dumêt Faria

perda de tal propriedade, ella vale quasi nada, não merece attenção" (Castro, 1887:56).

A mulher, considerada inferior e menos capaz, não era muito vista como grande ameaça social, ou pelo menos era percebida como mais facilmente contida e "domada" que os homens. No entanto, crimes e criminosas surgiram ao longo da história e fomentaram o debate sobre a existência de criminosas natas, as causas da criminalidade feminina, os crimes típicos de mulheres e, sobretudo, os estigmas atávicos que, reunidos, identificariam a mulher delinquente. Da mesma forma que com os homens, buscou-se definir grupos e categorias de mulheres que ofereceriam perigo social e, portanto, deveriam ser contidas. Essas características são, ainda hoje, responsáveis por uma herança preconceituosa não só contra as mulheres, mas contra determinadas características ligadas sobretudo à sexualidade feminina.

\section{A mulher criminosa}

As mulheres, ao longo da história, têm sido vítimas de uma armadilha social que as coloca numa posição de fragilidade e de docilidade, características responsáveis por uma construção de um estereótipo de pessoas menos capazes. Em matéria criminal, as mulheres também eram consideradas, fruto da tão aclamada docilidade, muito menos capazes de cometer crimes que os homens e quando os cometia, seria sempre sob a influência de um homem ou por motivos de paixão. Essa suposta incapacidade para o mundo do crime é um dos elementos que ajuda a fortalecer o universo feminino como inferior nos diversos campos sociais. Segundo Lima (2007:317/318),

Parece que não é dado ao universo feminino o direito à violência, somente podendo atingir seus fins maléficos com a malícia. Não lhes é permitida a prática de condutas que demonstrem a capacidade de inverter o papel social de inferioridade que lhes é imposto, o uso de violência por 
Mulheres no Tráfico de Pessoas

parte das mulheres choca, pois demonstra, em verdade, a equivalência dos seres na espécie humana.

A busca pela identificação e classificação dos criminosos teve também a mulher como um dos focos de pesquisa. Lombroso, em The Female Offender (1895), classificou a mulher criminosa como: criminosas natas, criminosas ocasionais, ofensoras histéricas, criminosas de paixão, suicidas, mulheres criminosas lunáticas, epilépticas e moralmente insanas. Pesquisas com mulheres presas na Itália identificaram sinais específicos que variavam a depender do crime cometido. Da mesma forma que com os homens, Lombroso mediu os crânios, estudou características faciais, os cérebros de mulheres consideradas criminosas e chegou a algumas características: assimetria craniana e facial, mandíbula acentuada, estrabismo, dentes irregulares, clitóris, pequenos e grandes lábios vaginais grandes, além da sexualidade exacerbada e dotada de perversão, caracterizadas normalmente pela prática da masturbação e do lesbianismo (Lombroso, 2004). De acordo com Lombroso, se a mulher tivesse quatro ou mais dessas características ela constituiria o que ele chamava de tipo completo, o tipo intermediário possuiria ao menos três dessas características e uma mulher comum teria, no máximo, duas dessas anomalias (Lombroso, 1980:103). Ressalte-se, no entanto, que a depender do estigma, bastava um para que a mulher fosse considerada depravada e perigosa, como era o caso do lesbianismo.

É interessante notar que os chamados estigmas atávicos não eram os mesmos para os homens e para as mulheres. Um exemplo é a aparência física. Normalmente, os homens perigosos tinham uma aparência não atraente, não à toa Lavater (17411801), em estudos sobre a fisionomia, tentava identificar traços físicos que pudessem distinguir o homem normal do criminoso, antecipando o que Lombroso definiu como Criminoso Nato. ${ }^{5}$

${ }^{5}$ Expressão sugerida por Ferri. Ver Pablos de Molina, 1992. 
Thaís Dumêt Faria

Com base em características somáticas, identificou o que chamou de "homem de maldade natural". Através das suas pesquisas, Lavater associava a beleza à bondade e a feiúra à maldade e, a partir desse pressuposto, defendeu o julgamento pela aparência (Shecaira, 2004:78) adotado por alguns juízes. Um deles, conhecido como Marquês de Moscardi, no século XVIII, é indicado como um dos precursores dessa forma de julgar, tendo concluído numa sentença: "ouvidas as testemunhas de acusação e de defesa $e$ visto o rosto e a cabeça do acusado, condeno-o" (Pablos de Molina, 1992:105). Foi ele quem criou o Édito de Valério - quando se tem dúvida entre dois presumidos culpados, condena-se o mais feio (Shecaira, 2004:79).

Para as mulheres, a beleza também sempre teve um papel relevante na construção dos estigmas criminosos. No caso dos crimes ligados à sexualidade, como a prostituição, a beleza era considerada definidor para medir a periculosidade da mulher, em outros casos, a aparência física era utilizada para minimizar situações em que a mulher era autora de crimes.

\section{O perigo da beleza... o perigo da prostituta}

No estudo da mulher criminosa, a beleza e a capacidade de sedução eram constantemente evocadas para justificar a periculosidade e a capacidade de cometer determinados delitos. Ou seja, no caso das mulheres, dependendo do crime, assossiavase a beleza ao perigo, uma vez que as mulheres mais atraentes teriam maior capacidade de ludibriar e enganar pessoas. As prostitutas eram consideradas parte de um grupo com o maior índice de criminosas, muito estudadas pelos teóricos da época e temidas por grande parte da sociedade, sobretudo pelo seu poder de "enganação" e sedução. Ainda segundo Lombroso (1980:107), a mulher criminosa tem a aparência normal, diferente do homem criminoso, por isso a maior dificuldade em identificá-la. Outro tipo de criminosa é o oposto da considerada mulher atraente, seria aquela com características físicas e comportamentais masculinas. 
Mulheres no Tráfico de Pessoas

Ela seria perigosa pela sua semelhança com o homem, ou seja, por ter rompido com o padrão de comportamento feminino tradicional.

Assim, o chamado "desvio sexual", seja quando a mulher apresentava comportamento masculino ou quando tinha uma erotização exarcebada para os padrões sociais, representava um sinal de periculosidade. Segundo Lima (1934:57):

Não passara desapercebido ao genio fulgurante de Lombroso, quando estudou, magnificamente, a mulher criminosa, que esta, embora encarcerada, excluida, por completo, do convívio social, não deixa nunca de encontrar opportunidade para mostrar ao visitante, ao director do presidio, ou á sentinella de serviço, a madeixa mais graciosa de sua cabeça...

Na discussão sobre o perigo da mulher atraente e bela, a figura da prostituta era sempre ressaltada e estudada pelos teóricos criminais. É interessante notar que as prostitutas eram normalmente estudadas como uma categoria a parte das mulheres. Lombroso, por exemplo, pesquisava a presença dos estigmas atávicos em grupos de mulheres e em grupos $e$ prostitutas e sempre encontrava os maiores índices no segundo. No entanto, o autor não levava em consideração, assim como não o fez no estudo do homem criminoso, a carga de estigmas preconceituosos, a exclusão social de que eram vítimas as prostitutas $e$, sobretudo, a possibilidade da existência de outros comportamentos, inclusive sexuais que não seguissem os padrões estabelecidos para as mulheres. Segundo Araújo (2007:45):

Das leis do Estado e da Igreja, com freqüência bastante duras, à vigilância inquieta de pais, irmãos, tios, tutores, e à coerção informal, mas forte, de velhos costumes misóginos, tudo confluía para o mesmo objetivo: abafar a sexualidade feminina que, ao rebentar as amarras, ameaçava o 
Thaís Dumêt Faria

equilíbrio doméstico, a segurança do grupo social $e$ a própria ordem das instituições civis e eclesiásticas.

A mulher tinha um conjunto de regras a serem seguidas para obedecer aos padrões, principalmente como esposa e mãe. A prostituta era vista como uma grande ameaça social, porque disseminava um modelo de liberdade e sexualidade que deveriam ser eliminados para evitar a repetição por outras mulheres. De acordo com Costa (2004:265):

A corrupção da moral feminina pela mulher perdida faziase, em primeiro lugar, pela exibição de seu comportamento sexualmente descontrolado. Mantendo relações sexuais por dinheiro e entregando-se à masturbação, à sodomia, $e$ práticas antinaturais do gênero, a perdida era um manual vivo da forma anti-higiênica de ser mulher.

A questão da criminalidade feminina era tão ligada à prostituição que, sobretudo durante a virada do século XIX para o $\mathrm{XX}$, o controle penal era voltado com muito mais ênfase para esse grupo de mulheres, restando para as demais o controle social e familiar. De acordo com Caleiro (2002:33):

Essa preocupação com a ordem, no que tangia às mulheres, seria exercida muito mais por instituiçóes como a família e a escola que promoviam a interiorização da ideologia masculina dominante, do que pelo aparelho policial. Este, direcionava sua atenção sobretudo numa faixa específica da população feminina, as prostitutas.

O controle penal, dessa forma, recaía com muito mais força sobre as prostitutas, consideradas previamente como criminosas, mesmo não havendo tipificação penal. No entanto, o controle social acabava tendo um peso muito maior na definição das criminosas do que o penal. Nota-se, portanto, que o mundo da prostituição sempre foi carregado de estigmas sociais que davam 
Mulheres no Tráfico de Pessoas

respaldo para atitudes preconceituosas, inclusive de repressão do Estado. Não é difícil perceber porque ainda há uma grande dificuldade em lidar com o crime de tráfico de pessoas para fins de exploração.

\section{As mulheres e o tráfico de pessoas: vítimas agressoras ou agressoras vítimas?}

Ao analisarmos brevemente a influência da Escola Postivista e sua classificação de mulheres criminosas, percebemos quanto a criminalidade era ligada a comportamentos sexuais que estavam fora do chamado "ideal feminino". Não à toa percebemos a carga preconceituosa sofrida pelas mulheres que fogem aos comportamentos tradicionais, seja por não terem condições ou por livre opção de buscarem outros caminhos.

A figura da mulher, como abordamos neste texto, era vista, $e$ ainda é, tradicionalmente, como ligada à doçura, à fragilidade e à sutileza, qualquer comportamento que não se adeque a essas características era, e continua sendo, visto com grande receio. Dessa forma, a ligação que as teorias da escola positivista fazia entre comportamentos "desviantes", sobretudo os sexuais, $e$ periculosidade permanece no imaginário social no que se refere à mulher. A intenção deste texto é fazer uma breve associação entre nossas heranças preconceituosas e o tratamento das vítimas de tráfico de pessoas para fins de exploração sexual e as mulheres que cometem tais crimes. Se por um lado esses estereótipos auxiliam na criminalização das vítimas, exatamente por possuírem comportamentos não desejados, por outro, as mulheres que participam da autoria do crime são vistas como menos agressivas e normalmente induzidas e comandadas por algum homem.

Com relação ao tratamento das vítimas de tráfico de pessoas, sabe-se que um dos maiores desafios é conscientizar, tanto a população quanto os técnicos das diversas áreas, que as mulheres traficadas para a exploração sexual, trabalhadoras do sexo ou não, foram vítimas de um crime. É importante ressaltar 
que o fato dessas mulheres atuarem como prostitutas no local de origem não descaracteriza o crime, nem mesmo seu consentimento. Segundo o Protocolo de Palermo, configura-se o crime desde que elas tenham sido vítima de engano, abuso de poder, fraude e outras circunstâncias que possam viciar sua vontade ou, claro, tenham sido vítimas de ameaças, violência ou qualquer ato que viole os direitos humanos. O que deve ficar claro é que as mulheres que são vítimas de tráfico de pessoas $e$ possuem o estereótipo de prostitutas, normalmente, são vistas $e$ tratadas como criminosas ou, ao menos, culpadas pelo que lhes ocorreu. Essas posturas acabam por fazê-las, além de vítimas do crime, vítimas do sistema que as criminaliza, ainda que não penalmente, mas, com certeza, socialmente, impedindo-as de ter acesso aos serviços de proteção e apoio. Os estigmas da criminalidade permanecem fortes na nossa sociedade $e$, com relação às mulheres, define as posturas e, sobretudo, as condutas sexuais que devem seguir. Não à toa, as mulheres que mais sofrem preconceitos são as que demonstram atitudes sexuais consideradas fora do "ideal feminino" - a homossexualidade, a prostituição, a sexualidade "exarcebada", livre, etc.

Perceber a origem dos estereótipos é o primeiro passo para desestigmatizar determinados grupos sociais e iniciar um processo de aceitação dos seres humanos, independente da forma como se apresentem ou conduzam suas vidas. Tratar homens e mulheres como dotados da mesma capacidade é não utilizar a sexualidade para punir as mulheres $e$ favorecer os homens. Exemplifico um caso em que um homem foi detido com uma adolescente que estava fazendo sexo oral em troca de dinheiro. Na delegacia, o homem, que praticava o crime de exploração sexual, foi liberado e a adolescente, vítima do crime, foi encaminhada à delegacia da infância e juventude. Essa é a sociedade em que vivemos, que tem a tendência a punir comportamentos sexuais femininos $e$ aceitar ou até incentivar os masculinos. $O$ trabalho no enfrentamento do tráfico de pessoas para a exploração sexual, sem dúvida, passa por um trabalho de conscientização da 
Mulheres no Tráfico de Pessoas

população sobre os diferentes comportamentos sexuais, principalmente das mulheres, diminuindo as punições sociais $e$ criminais a essas condutas.

Por outro lado, e esse não é o objeto deste artigo, as mulheres quando estão no pólo ativo de determinados crimes são vistas, algumas vezes, como incapazes de cometê-lo, passando pelo imaginário coletivo que estão sempre subordinadas a algum homem, porque não teriam "natureza" para cometer crimes mais violentos. A mulher seria agressora passional ou submetida ao controle masculino. Talvez por isso, algumas pesquisas sobre mulheres que cometem crimes atestem que a tendência é que tenham penas mais leves que as dos homens por entender que a periculosidade da mulher é muito menor que a do homem. Ora, sem analisar dados ou fazer um trabalho mais aprofundado de pesquisa, podemos ponderar sobre essas diferenças ditas "naturais". Se esperamos que as mulheres sejam reconhecidas como não inferiores aos homens, devemos esperar que lhes seja também reconhecida a capacidade de cometer crimes e de coordenar ações criminosas tanto quanto os homens. Claro que as mulheres estão menos envolvidas que os homens no mundo do crime, mas talvez isso se dê mais por uma questão de divisão social do mundo privado e público que por questóes de "natureza".

Este texto pretende, enfim, lançar algumas informações $e$ fomentar uma reflexão sobre os papeis dados às mulheres e sobre a história dos estereótipos que se formaram e que contribuem para o preconceito a determinadas condutas femininas. Conhecer a história é o primeiro passo para reconhecer nas diferentes pessoas o mesmo valor e a mesma importância, sobretudo para o tratamento do Estado na proteção dos seus direitos. 
Thaís Dumêt Faria

\section{Referências bibliográficas}

ANDRADE, Vera Regina. A ilusão de segurança jurídica: do controle da violência à violência do controle penal. Porto Alegre, Livraria do Advogado, 2003a.

- Sistema penal máximo X cidadania mínima: códigos da violência na era da globalização. Porto Alegre, Livraria do Advogado, $2003 b$.

AlvareZ, Marcos Cezar. Bacharéis, criminologistas e juristas: saber jurídico e nova escola penal no Brasil. São Paulo, Método, 2003.

ARAÚJO, Emanuel. A Arte da Sedução: Sexualidade Feminina na Colônia. In: PRIORE, Mary Del. (org.) História das Mulheres no Brasil. São Paulo, Contexto, 2007.

BATISTA, Nilo. Introdução crítica ao direito penal brasileiro. Rio de Janeiro, Revan, 2004a. $2004 b$.

CALEIRO, Regina Célia Lima. História e Crime: quando a mulher é ré Franca 1890-1940. Montes Claros, Unimontes, 2002.

CASTRO, Livio de. A Mulher e a Sociogenia. 1887.

CostA, Jurandyr Freire. Ordem Médica e Norma Familiar. Rio de Janeiro, Edições Graal, 2004.

DARMON, Pierre. Médicos e assassinos na "Belle Époque": a medicalização do crime. Rio de Janeiro, Paz e Terra, 1991 [Trad.: Regina Grisse de Agostinho].

Del Olmo, Rosa. A América Latina e sua criminologia. Rio de Janeiro, Revan, 2004 [Trad.: Francisco Eduardo Pizzolante e Sylvia Moretzsohn].

FARIA, Thaís Dumêt. A festa das cadernetas: o conselho penitenciário da Bahia e as teorias criminológicas brasileiras no início do século XX. Dissertação de Mestrado, Universidade de Brasília, 2007.

JAY Gould, Stephen. A falsa medida do homem. São Paulo, Martins Fontes, 2003 [Trad.: Luís Carlos Borges].

Lemgruber, Júlia. Cemitério dos Vivos. Rio de Janeiro, Ed. Forense, 1999. 
Mulheres no Tráfico de Pessoas

LimA, Estácio de. Inversão sexual feminina. Bahia, Livraria Científica, 1934.

LIMA, Paulo Marco Ferreira. A Mulher Delinqüente - Algumas Perguntas e Algumas Considerações. In: REALE JÚNIOR, Miguel e PASCHOAL, Janaina. (coords.) Mulher e Direito Penal. Rio de Janeiro, Forense, 2007.

LOMBROSO, César. O homem delinqüente. Porto Alegre, Ricardo Lenz, 2001 [Trad.: Maristela Bleggi Tomasini e Oscar Antonio].

and Ferrero, Guglielmo. Criminal Woman, the Prostitute, and the Normal Woman. Durham, Duke University, 2004 [Translated by Nicole Hahn Rafter and Mary Gibson]. and FERRERO, William. The Female Offender. Colorado, Fred B. Rothman \& Co, 1980.

Pablos de Molina, Antônio Garcia. Criminologia. São Paulo, Revista dos Tribunais, 1992 [Trad.: Luis Flávio Gomes].

Peixoto, Afrânio. Criminologia. Rio de Janeiro, Editora Guanabara, 1933.

RAUTER, Cristina. Criminologia e subjetividade no Brasil. Rio de Janeiro, Revan, 2003.

SHECAIRA, Sérgio Salomão. Criminologia. São Paulo, Revista dos Tribunais, 2004.

StEPAN, Nancy Leys. A hora da eugenia: raça, gênero e nação na América Latina. Rio de Janeiro, Fiocruz, 2005 [Trad. Paulo M. Garchet]. 